\title{
La expresión artística de la ciudad y su influencia en la pintura: el cartel y el graffiti
}

\author{
Artistic expression of the city and its influence in \\ painting: the case of poster and graffiti
}

\author{
RicARDO GONZÁLEZ GARCÍA \\ Universidad de Cantabria \\ gonzalezgr@unican.es
}

Recibido: $12 / 03 / 2016$

Aceptado: $18 / 04 / 2016$

\begin{abstract}
Resumen
El siguiente artículo centra su atención en dos de las manifestaciones artísticas de carácter público más presentes en la vida de la urbe, para analizar las diferentes influencias mutuas que podemos encontrar, desde su aparición, entre éstas y la pintura. Esto significa contrastar esta última - una disciplina con gran tradición histórica, considerada un medio de reproducción lento de la imagen-, a un medio, en principio, como el cartel, que hace su aparición en la escena de la ciudad en el siglo XVIII, y a otro como el graffiti, en segundo lugar, cuya aparición situamos en el último cuarto del siglo XX. Considerando una visión de conjunto, que nos acerque a las dos expresiones públicas que tratamos, y sin entrar todavía en consideraciones estéticas, hemos de aclarar que, en cuanto al mensaje que sendos medios ejercen en la masa social, podemos establecer al cartel como una manifestación cerrada y objetiva; al servicio de un fin comercial o ideológico claro y definido que, en la mayor parte de las ocasiones, posee un lugar destinado para su colocación, mientras que el graffiti es un medio más abierto, subjetivo y, por lo tanto, anárquico en cuanto a su ubicación, que nos acerca a la voz de las tribus urbanas, a las expresiones individuales pero identificativas de ciertos grupos que va generando la ciudad, como indicativo de los intereses y las modas que mueven, sobre todo, a los ciudadanos más jóvenes.
\end{abstract}




\title{
Palabras clave
}

Ciudad, expresión social, cartel, graffiti, pintura, influencias.

\begin{abstract}
The following article focuses on two of the art forms of public character more present in the life of the city, to analyse the different mutual influences we can find, since its inception, between them and painting. This means contrasting the latter - a discipline with great historical tradition, considered a means of slow reproduction of image-, at an average, in principle, as the poster, which makes its appearance on the scene of the city in the eighteenth century, and other like graffiti, secondly, whose appearance we place in the last quarter of the twentieth century. Considering an overview, that brings us to the two public expressions we tried, without yet going into aesthetic considerations, we must clarify that, in terms of two separate message in the mass media exert social can establish the cartel as a manifestation closed and objective, the service of a clearly defined commercial or ideological purpose that in most cases, has a place intended for placement, while graffiti is a more open, subjective medium and, therefore, anarchic as to its location, which brings us to the voice of urban tribes, but identifying individual expressions of certain groups that is generating the city, as indicative of the interests and fashions that move, especially younger citizens.
\end{abstract}

\section{Keywords}

City, Social Expression, Poster, Graffiti, Painting, Influences.

Referencia normalizada: GONZÁLEZ GARCÍA, RICARDO (2016): “La expresión artística de la ciudad y su influencia en la pintura: el cartel y el graffiti". Arte y Ciudad. Revista de Investigación, no 9 (abril), págs. 183-204. Madrid. Grupo de Investigación Arte, Arquitectura y Comunicación en la Ciudad Contemporánea, Universidad Complutense de Madrid.

Sumario: 1.- Introducción: la expresión urbana de la masa social. 2.- Retroalimentaciones mutuas entre el cartel y la pintura. 3.- Retroalimentaciones mutuas entre el graffiti y la pintura. 4.- Conclusiones. 5.- Bibliografía. 


\section{1.- Introducción: la expresión urbana de la masa social.}

Símbolo de la etapa moderna a la que se va acostumbrando la cada vez más acelerada vida del ser humano, centrada en las acciones culturales que comienzan a desarrollarse en las nuevas ciudades que emergen con la Revolución Industrial, el cartel servirá de soporte a la ideología que los diferentes grupos sociales y políticos manifiestan. Además, su fuerte carácter de persuasión será algo que los empresarios comerciales no dudarán en aprovechar. Por ello, podemos establecer dos diferenciaciones fundamentales en el cartel: la política y la comercial. Aparte, en cuanto a su técnica, no debemos olvidar que la historia del cartel parte de la invención de la imprenta y se desarrolla a la par que lo hacen las distintas técnicas de reproducción gráfica, además de haber sido realizado, en ocasiones, mediante técnicas directas, relacionándolo directamente con la pintura.

Según su definición, el cartel es un papel impreso con una representación icónico-escritural que se coloca en un lugar público para anunciar o hacer saber alguna cosa. Por ello, como medio de comunicación de masas que es, se dirige a todo tipo de público. Dentro del abanico de medios de este tipo que encontramos en nuestra sociedad contemporánea, el cartel se ha presentado con apariencias muy variadas dependiendo de la época en que se ha concebido, factores que dependen, además, de las técnicas a las que hemos aludido y, sobre todo, a los movimientos artísticos paralelos a él, así como a las circunstancias económicas, comerciales, sociológicas, políticas e históricas. Es por ello que acometer un estudio del cartel en profundidad conllevaría abordarlo desde múltiples puntos de vista.

Pero volviendo a su origen específico, podemos establecer sus precedentes directos en los emblemas artesanos o la heráldica medieval de la Francia del siglo XVIII, país que, a partir de la Revolución Francesa y la declaración de los Derechos Humanos, parece enarbolar la bandera del progreso occidental de la era moderna, junto con Inglaterra, donde se inicia la Revolución Industrial. Acontecimientos que catalizan el crecimiento de las ciudades y, con ello, la proliferación de eventos, productos o movimientos ideológicos dirigidos a un alto número de receptores, que mediante el cartel pueden ser anunciados. En ese sentido, ocurre en Francia un curioso fenómeno que potenciará el desarrollo del cartelismo; el hecho de que, en determinado momento, llegaran a confundirse anuncios de eventos con avisos oficiales. Tal y como comenta Roman Gubern, este hecho: 
(...) motivó en Francia una ley, en julio de 1791, que prohibió los anuncios murales con letra negra sobre fondo blanco, para evitar su confusión con los avisos oficiales emanados de la Administración. Esta restricción tendría el saludable efecto de empujar a la publicidad cartelística hacia el campo de lo icónico y el uso del color (Gubern, 1997: 53).

A partir de esa potenciación artística que comienza a adquirir el medio del cartel en el siglo XIX - donde muchos autores señalan el origen de ese cartel 'artístico' que llega hasta nuestros días-, como pionero del cartelismo que se desarrollará posteriormente, hemos de citar a Jules Chéret (París, 1836), que ya en 1866 comienza a producir carteles litográficos en París con su prensa en color. Digamos que Chéret marca las pautas de un cartel de diseño novedoso y sobrio que otros muchos autores seguirán posteriormente. Aunque también, como apuntábamos, existirán carteles realizados manualmente que se conciben como obra única, su aparición como medio de masas supone el cruce entre lo tecnológico y lo cultural; la unión de la cromolitografia, destinada a grandes superficies de impresión, y los intereses propagandísticos de eventos, como ferias, circos..., a los que más tarde se unirán los intereses políticos.

Este modo de publicidad se desarrolla con gran esplendor en el siglo XIX, en un recorrido paralelo al que se produce con la publicidad impresa en prensa y revistas. El hecho de que su conformación estética corra pareja a los distintos movimientos artísticos es debido a su: "extraordinaria permeabilidad plástica al gusto dominante" (Gubern, 1987: 184), estableciéndolo como modelo de estudio para entender las claves del arte moderno.

Por otro lado y con una aparición mucho más reciente, como punto equidistante entre el cartel y la pintura mural podemos situar al actual graffiti que, conservando cuestiones que lo pueden emparentar con la misión desempeñada por el cartel, parece perder de vista al papel como soporte - aunque alguna corriente del postgraffiti lo vuelva a recuperar-, para extenderse sobre el muro con total libertad. Las influencias mutuas que podemos encontrar en su relación con la pintura, e incluso con el cartel, son difíciles de calibrar, pues el graffiti por sí mismo puede ser considerado como pintura o, según lo dicho, también acude al cartel como recurso para su expresión en determinadas ocasiones. Cuestiones que, sin lugar a dudas, borran los límites existentes entre uno y otro medio, siendo el contexto en el que se den el único indicativo que nos haga saber de qué estamos hablando en cada caso. En esa onda, el 
único órgano que nos puede servir de medida para la distinción es la institución artística; el circuito formado por la propia academia, encargada de registrar y analizar los distintos comportamientos y expresiones artísticas, las galerías y los museos de arte.

Hablar de graffiti, en definitiva, es hacerlo de la ciudad, dado que surge directamente de ella, representando el contexto que enmarca su expresión. Una ciudad entendida en su sentido móvil, flexible y que se adapta a los diferentes movimientos sociales que alberga; con su propia política de convivencia social y transformación. Una sociedad que, en su autoafirmación, demanda su propio territorio, dando rienda suelta a sus manifestaciones, en este caso, en forma de pintadas sobre los muros o cualquier otro elemento de transporte o mobiliario urbano. Aquello que en su día pudo comenzar como una reivindicación tribal, se ha sofisticado en forma de interesantes propuestas que abandonan, incluso, el muro que en su día sirvió de soporte; acciones a medio camino entre la instalación y el aprovechamiento de los recursos que plantea la ciudad, que borran el límite del arte entendido como algo que tenga que hallarse necesariamente dentro de un museo o una galería.

Pero sin perder los inicios del asunto, podemos decir que el graffiti es síntoma del conflicto y la lucha intrínseca que poseen los movimientos sociales alternativos, al reclamar su hueco y existencia en la ciudad. Espacio que demandan identificándose con ciertos ideales que proyectan al exterior en forma de información; símbolos e imágenes que establecen su propia memoria. Marcas que posibilitan que sus miembros se reconozcan entre sí, en acciones que, a veces, implican cierta clandestinidad dentro del espacio público. En ese sentido, el graffiti muestra una riqueza inagotable de significados y matices que quizá, para un espectador no especializado en su código, pasen desapercibidos, pero que, sin embargo, contienen su propia semántica y gramática de comunicación interna. Respecto a ello Maffesoli comenta:

Sus expresiones pueden estar ciertamente muy diferenciadas, pero su lógica es constante: el hecho de compartir un hábito, una ideología, un ideal, determina el ser conjunto y permite que éste sea una protección contra la imposición, venga de donde venga. (Maffesoli, 1987: 67)

Aunque el graffiti sea relativamente reciente, si tratamos de buscar sus antecedentes históricos podemos comprobar lo siguiente: de algún modo, la expresión de la masa social ha sido algo que, aunque tímidamente según la libertad 
de expresión de cada época, siempre ha estado presente. ¿Acaso no podemos entender las pintadas de las primitivas cuevas como se entiende hoy el graffiti?, ¿o el arte sumerio tallado en pared, el realizado en el arte egipcio, o aquel procesado en las casas de la antigua Grecia, en el pueblo maya o en los murales religiosos que se pintaban en las iglesias?. Por ejemplo, acercándonos más a esa masa social que queremos poner de relieve, entre los romanos era costumbre la escritura ocasional sobre muros y columnas, esgrafiada y pintada en latín vulgar, donde se podían leer consignas políticas, insultos, declaraciones de amor, etc., junto a caricaturas y dibujos. Inscripciones que se han encontrado en cuevas-santuario, muros enterrados, catacumbas..., o en las mismísimas ruinas de Pompeya y Herculano. En esa línea, pero de una época más reciente, también se conocen ejemplos de iniciales o seudónimos, que los marineros y piratas dejaban sobre las piedras o las grutas tras su viaje, al pisar tierra. Aunque muchas de estas manifestaciones no sean producto exclusivo de la expresión del pueblo, podemos decir que el ser humano ha mantenido una necesidad por dejar su impronta sobre las paredes que delimitan entre su espacio privado y el público, de un carácter más vulgar o popular que esa disciplina pictórica que, en tiempos, sólo sirvió para el deleite de unos pocos.

Pero lo que hoy denominamos graffiti, como tal, posee su propia historia, que comienza, en Nueva York, en los últimos años sesenta y principios de los setenta, donde se producen nuevas formas culturales derivadas de los ambientes marginales de la ciudad, que pretenden romper con los patrones marcados por los mecanismos de control social. Ante esa lucha, el género musical del soul, de los guetos de Nueva York, originará una cultura hip hop mucho más combativa y reivindicativa. La expresión gráfica de este tipo de movimientos culturales será el graffiti, que genera una terminología y un lenguaje icónico y textual autóctonos y originales, cuyo estudio se torna imprescindible para comprender muchas de las formas adoptadas por el arte contemporáneo, posteriores a su aparición.

\section{2.- Retroalimentaciones mutuas entre el cartel y la pintura.}

De vuelta al cartel cromolitográfico que realiza Jules Chéret, técnica que descubre, podemos observar que se ve directamente influenciado por la pintura, cuando analizamos su representación; figuras en ángulo contrapicado de las que G. B. Tiépolo parece ser su referente, para insinuar al espectador la visión de un escenario teatral. Es tal el respeto que profesa hacia las re- 
presentaciones que plasma en sus carteles $-\mathrm{y}$ hacia sus referentes pictóricos - que éstos se caracterizan por una escueta información textual, destacando el tratamiento repetitivo la figura femenina tratada de forma alegre, sensual, dinámica..., encarnada, en la mayoría de las ocasiones, por actrices y bailarinas.

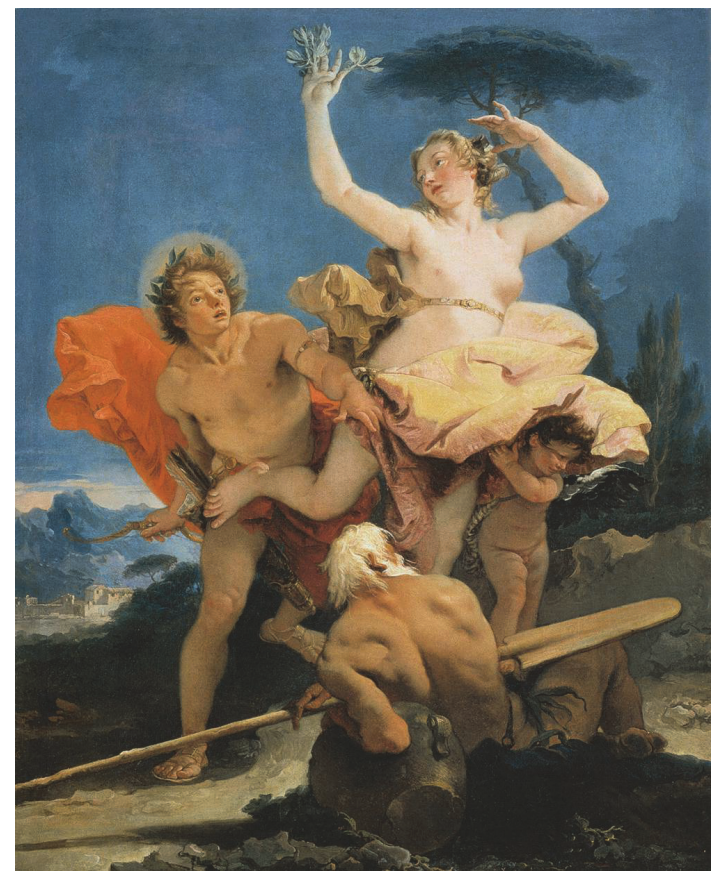

Figura 1. Giovanni Battista Tiepolo, Apolo y Daphne, 1745 (Fuente: WGA22293.jpg, public domain)

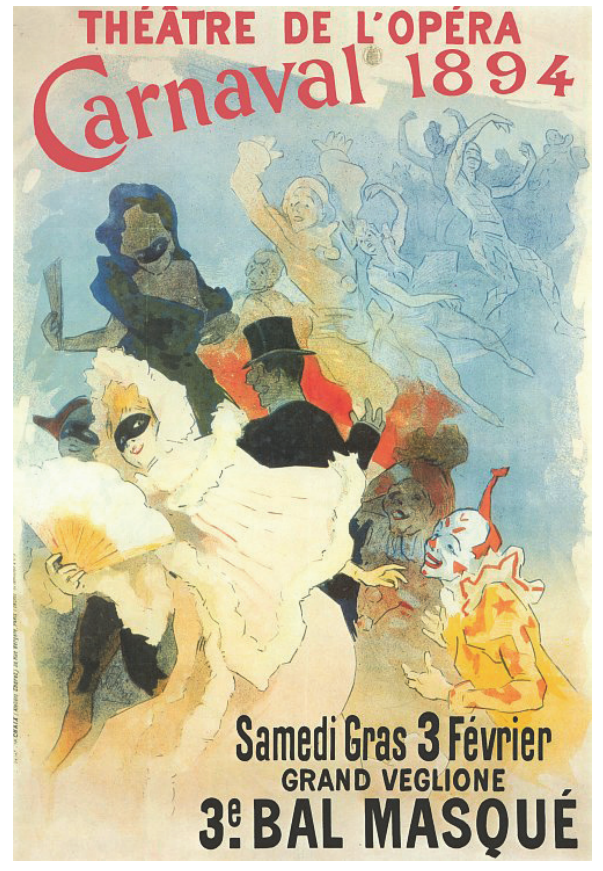

Figura 2. Jules Chéret, Carnaval, 1894 (Fuente: WCommons public domain)

Desde ese momento el cartel comienza a adquirir identidad propia y ya, según el cartelista francés Cassandre: "no puede ser considerado como un cuadro de caballete ni un decorado de teatro, sino 'algo aparte', aunque a veces se sirva de los medios del uno y del otro” (AA.VV.: 2001, 79). En ese sentido, los antecedentes históricos directos que influyen en la estética del cartel en sus primeras etapas, será la tradición de la pintura mural europea, como en el caso señalado de Tiepolo, de quien se imitará su forma original de situar las figuras en la escena de la composición, y la pintura japonesa, de vivo colorido, que comenzará a ser conocida en Europa durante ese periodo. 
En alardes de virtuosismo, Cheret dibujará directamente sobre la piedra litográfica, "devolviendo así a la litografía ese carácter de medio directo de creación que había tenido con Goya y otras figuras de comienzos de siglo" (Barnicoat, 1972: 8). Aparte de la comentada influencia de Tiépolo, como señala Barnicoat: "se puede detectar en su técnica de dibujo cierta similitud con Fragonard y Watteau" (Barnicoat, 1972: 8). Sus carteles - con tendencia muralista - aparecieron en un París que se hallaba en plena reconstrucción tras la Revolución, como la forma artística y vital a la que estaba tendiendo la ciudad con su necesaria remodelación, llegándose a decir que podían suponer un caso de exhibición pública de arte en la calle, lo que podemos considerar un antecedente al arte urbano y graffiti que hoy conocemos.

Como decimos, los carteles de Chéret combinan una novedosa técnica y la interpretación tradicional del arte mural, que se mezcla con el idioma popular de eventos como circos y ferias de diseños vivos y alegres. El hecho significativo de la consideración de Cheret como pintor mural, más que cartelista publicitario puro, es que tenía un amigo: Madaré, que, una vez terminada la composición, añadía los textos a las representaciones del primero.

Así, con su arte funcional y espontáneo, llegó a crear un amplio abanico de estereotipos femeninos de extrovertida liberación y felicidad, que serían seguidos por buena parte de los pintores que, por la época, comenzaban a experimentar sus composiciones en un París que abría sus puertas artísticas a aquellos que protagonizarían lo que sería un cambio radical. Por ejemplo, Henry van de Velde, uno de los grandes portavoces del Art Nouveau, menciona a Chéret como uno de los más importantes precursores de este movimiento. Aunque sería en Seurat donde éste tuvo un impacto más significativo, como podemos observar en los cuadros Le Chahut (1890) y Le Cirque (1891), que se adentran, dejando a un lado el entorno natural propio de los impresionistas, en una atmosfera circense propia de Spectacle-Promenade de l'Horloge, cartel realizado por Chéret diez años antes.

Como continuador ineludible de la escuela que iniciara Chéret con este nuevo arte público, encontramos a Henri de Toulouse-Lautrec que, a diferencia de los discípulos del propio Chéret, como Georges Meunier o Lucien Lefévre, quienes representaban la vida más superficial de los habitantes de la ciudad, plasmará las vidas interiores de aquellos, a partir de su dramática experiencia 
personal, mediante formas caricaturescas, irónicas y satíricas en composiciones sencillas y de tonos planos, que poseen un carácter más abocetado y fresco que sus pinturas. Fórmula que será retomada en la obra de muchos pintores de la primera mitad del siglo XX. Como dice Barnicoat: "Lautrec relaciona el cartel con la evolución futura de la pintura al tiempo que consolida esa nueva forma de expresión" (Barnicoat, 1972: 24). Al comparar los carteles de Lautrec y Chéret hubo críticos, como el inglés Charles Hiatt, que destacaron el aire 'feo' e inquietante de Lautrec, en lo que, sin embargo, residía un oculto atractivo, en contraste con la alegría y el agrado que transmitía Chéret.
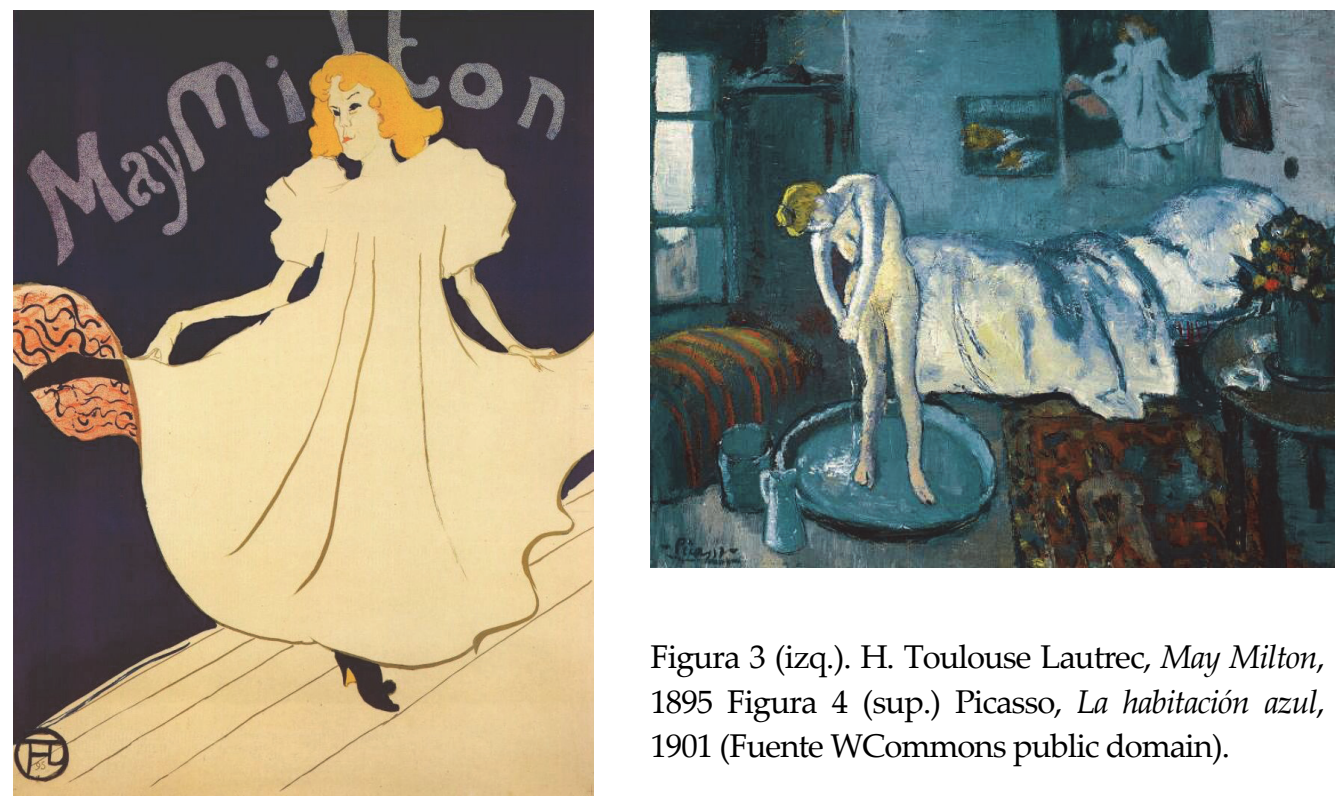

Figura 3 (izq.). H. Toulouse Lautrec, May Milton, 1895 Figura 4 (sup.) Picasso, La habitación azul, 1901 (Fuente WCommons public domain).

Lautrec, a pesar de su corta vida, dejó un legado importante para la historia del arte en general y para la del cartel en particular; como dirá Facundo Tomás, Lautrec supondrá "la definitiva apertura de la puerta de una nueva figuración bidimensional, capaz no solo de acelerar el camino de democratización de la imagen, sino también de profundizar y ampliar en una nueva línea formal el pensamiento visual" (Tomás, 1998: 247). Cuestión que ayuda a establecer el carácter directo del cartel como forma artística, cosa que influiría sobremanera en los jóvenes como Pablo Picasso que, por aquellos momentos, comenzaba su andadura artística. Influencia que demuestra su cuadro La habi- 
tación Azul (1901), composición en la que colgando de la pared aparece May Milton, de 1895, realizado por Lautrec. A partir de la impronta dejada por Lautrec, el lenguaje visual del cartel se irá sintetizando paulatinamente.

En el siglo XX podemos marcar el desarrollo de la evolución del cartel sincronizada con la estética de los diferentes movimientos y estilos que se irán sucediendo en las artes plásticas. Tras Chéret, en la etapa que va hasta la I Guerra Mundial, los carteles se realizaron principalmente por pintores, por lo que se nota una clara influencia pictórica en sus ejecuciones. Ya en la etapa del 'fin de siecle', antes de comenzar la frenética progresión de estilos característica de las primeras Vanguardias, aparece el Art Nouveau que aportó a la técnica del cartel sus propias pautas decorativas y ornamentales, derivadas de las formas orgánicas cuya interpretación iba unida a la idea de 'lo nuevo', así como a su intención de integrar el arte en la sociedad.

Proceso histórico, en relación a la expresión del cartel como medio, que la escuela de la Bauhaus tratará de racionalizar, sentando las bases de lo que hoy conocemos como diseño gráfico. En ese sentido, la síntesis y la abstracción desarrollada por el arte de vanguardia en los países nórdicos, contribuirán al desarrollo de parte de las premisas que persigue la mencionada escuela.

En definitiva, el cartel aparece en la ciudad como indicativo y aglutinador del intercambio cultural de cada época, donde las influencias entre estilos se manifiestan abiertamente. En esa convergencia de los intereses populares, en las representaciones qu ofrecen los carteles, podemos comentar el caso de Alphonse Mucha, quien llega a París en 1890 con una obra cercana al Art Nouveau y que cuando, más tarde, se traslada a Nueva York, impregna sus carteles con la presencia de actrices de la época que allí encuentra. Todo ello marca un tiempo floreciente para el cartelismo, al que comenzarán a dedicársele exposiciones y volúmenes sobre su historia, hecho que también provocó que muchos aficionados comenzaran a coleccionarlos.

Así pues, el cartel comienza a representar un claro referente cultural, siendo igualmente una fuente de información visual en la que muchos artistas se fijan. Fue tal la influencia que ejerce el cartel en determinados artistas que, por ejemplo, si nos detenemos en el movimiento simbolista, podemos observar que muchas de sus composiciones -con sus temas alegóricos, colorido subjetivo y llamativa imaginería-, se asemejan mucho a carteles. Desde las 
aportaciones de este movimiento, esa misma similitud iconográfica supondrá un pilar donde sustentar desarrollos futuros de la pintura y el grafismo, ya que su uso simbólico de la realidad opta por disponer los elementos en la composición de un modo no convencional, como podía estarlo haciendo, hasta ese momento, otro tipo de pintura de carácter más naturalista.

Muestra de esa poderosa unión que ata al simbolismo con la técnica del cartel, son las declaraciones de Maurice Denis en 1920:

Lo importante es encontrar una silueta que sea expresiva, un símbolo que, sólo por su forma y colorido, sea capaz de atraer la atención de la multitud, de dominar al transeúnte. El cartel es una bandera, un emblema, un signo: in hoc signo vinces. (Barnicoat, 1972: 49)

Quizá de un modo diferente al que quería transmitir Denis, efectivamente como bandera es como acogen el uso del cartel los movimientos políticos que se agitan durante el siglo XX. Cuestión que se torna panfletaria de la concienciación patriótica y añadido desprecio por el enemigo en tiempo de guerra. Ejemplo notable de ese tipo de cartelismo lo encontramos en la Revolución Soviética de 1917, donde se dan cita estéticas propias del futurismo, el suprematismo y el constructivismo, movimientos que parecen anticiparse a la imposición de una guerra mecanizada.

El cartelismo realizado durante las vanguardias rusas, proveerá al universo visual soluciones en términos de composición basadas en el fotomontaje, con un diseño y una tipografía absolutamente inéditos para la época. Hecho que viene alimentado por la transversalidad que comienza a fomentarse con el lenguaje cinematográfico. Fue tal el éxito que el cartelismo obtuvo en la Unión Soviética, que un decreto oficial pasó a regularlo según criterios pedagógicos y formales, algo que desembocaría en una imposición estilística y conceptual denominada 'realismo socialista', durante la era de Stalin. Un reflejo más cercano de este cartelismo soviético, lo podemos encontrar en el realizado en España durante la Guerra Civil, sobre todo en los realizados por Josep Renau (Valencia, 1907), quien salpicará su obra con unos tintes más expresivos, propios de la tradición pictórica española del barroco Siglo de Oro.

En nuestro relato sintético del tema tratado, no podemos olvidarnos de Cassandre, seudónimo de Jean-Marie Moreau, exponente de la línea europea y seguidor de la corriente mecanicista promulgada por el lenguaje de los mo- 
vimientos artísticos formales, quien realiza unas declaraciones en 1933 que sentarán las bases del futuro especialista en comunicación audiovisual, escindiendo los medios pintura y cartel, que hasta el momento parecían haber estado recorriendo un camino paralelo que podía confundirse en ocasiones:

Es difícil determinar el lugar que corresponde al cartel entre las artes pictóricas. Unos lo consideran una rama de la pintura, lo cual es erróneo; otros lo colocan entre las artes decorativas y, en mi opinión están igualmente equivocados. El cartel no es ni pintura ni decorado teatral, sino algo diferente, aunque a menudo utilice los medios que le ofrece uno a otro. El cartel exige una absoluta renuncia por parte del artista. Este no debe afirmar en él su personalidad. Si lo hiciera, actuaría en contra de sus obligaciones (Barnicoat, 1972: 80-81).

De lo que se destila que, aunque haya interferencias mutuas, el cartel posee un carácter funcional que lo distancia de la pintura. Por tanto, el cartel debe atender a fines promocionales, dirigidos a una fácil asimilación por parte de toda clase de personas, pasando la expresión del artista a segundo plano. Para confirmarlo Cassandre subraya:

La pintura es un fin en sí misma. El cartel es sólo un medio para un fin, un medio de comunicación entre el comerciante y el público, algo así como el telégrafo. El diseñador de carteles tiene el mismo papel que el funcionario de telégrafos; él no inicia las noticias, simplemente las transmite. Nadie le pregunta su opinión, sólo se le pide que proporcione un enlace claro, bueno y exacto (Barnicoat, 1972: 81).

Como los carteles van surgiendo en paralelo a los distintos movimientos artísticos, la historia del cartel y la pintura siguen entrecruzándose inevitablemente en una larga andadura que llega hasta nuestros días. Una presencia de los carteles que se magnifica aún más con la expansión de la publicidad. En ese sentido, podemos recordar la anécdota de Willen de Kooning, nacido en Holanda en 1906, que cuando se traslada a Estados Unidos, en 1928, se siente fascinado por las grandes vallas publicitarias que allí encuentra. Este hecho le sirve de revulsivo para trasladar esa sensación a sus pinturas, sintiéndose, a su vez, intrigado por la banalidad conceptual que se desprendía de muchos de esos anuncios que allí encuentra. Thomas B. Hess llegó a afirmar que la conocida serie Woman, de los cincuenta, fue concebida en términos de gran publicidad, dirigida al gran público:

De Kooning estaba pensando en los ídolos femeninos norteamericanos de los anuncios de cigarrillos (en un estudio....recortó la boca de un pequeño anuncio 
de Camel - 'be kind to your T-zone' - y lo pego sobre el rostro), en las muchachas cuyas fotografías desfilan por toda la ciudad sobre los laterales de las furgonetas de correos, y en las modelos de sus extraordinarios pechos (un ejemplar particularmente coposo colgaba de la pared del estudio). Y así, su comprensión de nuestros modernos iconos modificaba la presencia irónica de la Mujer; la Diosa Negra tiene una sonrisa torcida (Barnicoat, 1972: 202).

Al hilo de ese tipo de cartel realista que comenzará a invadir la publicidad, del que el arte pop dará buena cuenta, podemos comentar que la técnica del collage -introducida en la pintura por el cubismo-, cuya finalidad, en principio, era introducir cualidades táctiles en la superficie de la obra, derivará hacia la introducción de la imagen en sí misma, utilizándose los propios carteles como parte integrante de la obra. Ejemplo de ello, y haciendo un salto cuantitativo y cualitativo, desde este sintético relato, de lo que ha supuesto la extensa relación entre el cartel y la pintura, como resumen híbrido de ambas propuestas y enlace con el graffiti, podemos recordar a aquellos seguidores de la técnica del Décollage, opuesta al collage, es decir: la imagen se obtiene cortando, rasgando o eliminando partes de la original.

En un viaje que Wolf Vostell realiza, en 1954, a París, coincide con el término 'décollage' en el la portada de Le Figaro, lo que le anima a la creación de obras que denomina Dé-coll/ages. Hasta finales de los sesenta, Vostell, como introductor del término en la práctica artística, crea obras con la técnica Dé-coll/age como Rue de Buci, de 1960, o Coca-Cola, de 1961. Así, Vostell amplía este concepto a sus happenings y lo convierte el principio fundamental de su obra. Dicha práctica supone la "estética de utilizar lo destruido y que pertenece ya al anonimato, bajo un concepto crítico muy radical de raíz duchampiana, como una nueva realidad artística" (Lozano, 2000: 16) - según comenta María del Mar Lozano-, que comenzará a ser frecuentada por artistas como Francois Dufrene, Jacques Villeglé, Mimmo Rotella y Raymond Hains, desde el movimiento del Nuevo Realismo, corriente artística francesa contrarréplica al Pop Art, con el apoyo crítico de Pierre Restany y el artista Yves Klein.

Más reciente, pero con un sentido contrario al de Vostell, Albert Oehlen (Krefeld, 1954), en su dilatada y diversa trayectoria usa, a veces, carteles publicitarios, en una clara alusión a la capacidad de seducción de la propaganda en contraste con la pintura, que acaba constituyéndose como crítica a la publicidad. Sus pinturas son de aspecto suntuoso, con clara determinación a 
errar en su ejecución para desviar cualquier norma formalista que pudiera quedar en la pintura. Oehlen trata así de negar el cuadro como un acto primordialmente político, mientras se deshace del idioma visual de consumismo. Su peculiar apuesta por la pintura $-\mathrm{y}$ a sabiendas de la mitología que acarrea - supone una reflexión sobre el papel de ésta frente a los nuevos medios. Sus combinaciones entre medios y estilos dan como resultado pinturas híbridas que presentan una protesta estética, más que una resolución. Su obra se compone de una amplia variedad de obras que ha denominado como arte 'post-no figurativo', donde desafía continuamente a lo convencional y rutinario. Es interesante destacar lo que el mismo Oehlen explica, al referirse a cómo el pop y el cartel publicitario ha influido en la vida de la sociedad y en el arte, destacando, asimismo, su acogida y versatilidad:

(...) el pop ha transformado el mundo, y ése es un aspecto que me parece sumamente interesante. Porque el mundo entero se sirve del pop. Se divierte con él. Cualquier persona puede colgar un cartel publicitario en la pared de su casa y disfrutar al contemplarlo. En realidad, podría decirse que la humanidad, que es maleable, reacciona positivamente al pop, y que, al margen de la industria publicitaria, la gente en general -incluidos los llamados artistas - puede manejarlo a su antojo' ${ }^{1}$.

\section{3.- Retroalimentaciones mutuas entre el graffiti y la pintura}

Lo que en el medio del graffiti comienza siendo la inscripción de una firma, denominada $\mathrm{tag}^{2}$, se va complicando paulatinamente con la incorporación de imágenes provenientes del cómic, dibujos animados, caricaturas, etc., lo que hace que las obras vayan aumentando su tamaño considerablemente. Todo esto desembocará en lo que, en los noventa, se denominará, de modo más genérico, Street art y Postgraffiti, que engloba un tipo de manifestación que ya no se adscribe solo al muro necesariamente y que desarrolla técnicas a base de utilización de plantillas, carteles o pegatinas, lo cual implica una preparación previa del proyecto a realizar, para que el trabajo en la calle se realice de una

\footnotetext{
${ }^{1}$ Albert Oehlen en entrevista con Christian Domínguez (2013): “Conceptos cromáticos modernos. Conversaciones de Christian Domínguez con Albert Oehlen" (AA.VV. 2013: 26).

2 Un tag o tager ("etiqueta") es una firma o un acrónimo de una persona o un grupo de personas, generalmente Crews. Para los tags, con el nombre de la Crew, se suelen utilizar abreviaturas o simplemente las siglas. Un tag no es solo una firma, mediante un apodo o alias supone una expresión de estilo propio.
} 
forma más fluida. A partir de esa etapa, el arte urbano parece algo más serio y consensuado, por lo que comienza a introducirse en el ámbito de los museos y galerías, llegando a formar parte de grandes colecciones.

Desde esa confrontación, entre el arte urbano y el arte 'de galerías', representantes del arte pop comenzarán a cerciorarse del potencial icónico que supone el graffiti, algo que éstos comienzan a asimilar y a extrapolar a su obra, como una descontextualización progresiva de su inicial función urbana. Aun así, muchos graffiteros, que aún trabajan en la calle, menosprecian a aquellos que han decidido entrar a formar parte de ese circuito de galerías o han sido absorbidos por la institución artística, considerando que esta clase de producción deja de ser graffiti. En cambio, los graffiteros que exponen su creación en el mencionado circuito, utilizan en su estética los recursos del graffiti tradicional, no desdeñando compartir su actividad de galería con el trabajo en la calle del que partieron, aunque en la mayoría de los casos se acaben distanciando. Ese alejamiento del contexto de origen, ocasiona variaciones estéticas que dan lugar a nuevas tendencias, que pueden llegar a dialogar con las corrientes artísticas tradicionales, mediante el uso de su propio metalenguaje adquirido fruto de su raíz combativa y antiartística, que podemos relacionar con el movimiento dadaísta.

En esta línea postgraffitera Banksy (Bristol, 1974) es uno de sus representantes más laureados por el público, aunque su identidad real parezca ser un misterio. Al modo en que Duchamp realizara sus ready-mades recíprocos, como puede ser L.H.O.O.Q. (1919), Banksy interviene reproducciones de cuadros de la historia del arte para establecer un diálogo con su estética postgraffitera, cuyo sello ya lleva implícito una carga de humor a la vez que una crítica al sistema. Tal es el caso de algunas piezas que expuso en el Museo de Bristol - su ciudad natal-, en el año 2009, bajo el título Banksy Versus Bristol Museum. Ante estas obras, Banksy pone en juego una estrategia transgresora, deudora del punk, para la que ningún artista - incluido su compatriota Damien Hisrstqueda al margen de su ironía. En definitiva: "refleja el antagonismo existente entre las instituciones artísticas establecidas y la naturaleza ilícita de su actuación en la esfera pública"3, un hecho que nos informa de que, en realidad - más allá del grafitti callejero que tanto ha practicado a partir de plantillas estarci-

${ }^{3}$ Hans Werner Holzwarth, ed. (2008): «Banksy», en Art Now Vol. III. Taschen. Köln, p.52. 
das - son los medios de comunicación, y no tanto la calle o la galería, el contexto principal del discurso que pretende transmitirnos.

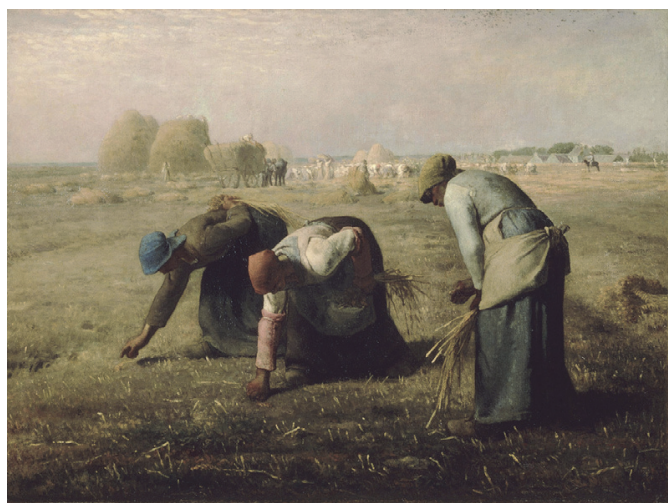

Figura 5. Jean-Françoise Millet. Las espigadoras (1857) (Fuente: WCommons public domain).

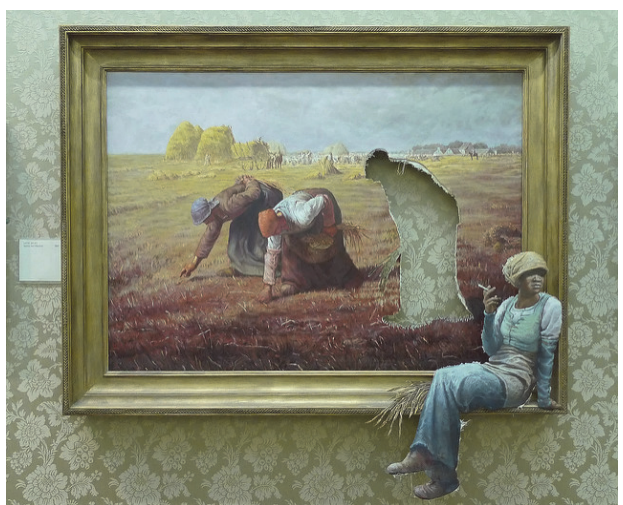

Figura 6. Banksy, Agency Job (2009) (Fuente: artforus.files.wordpress.com).

Pero volviendo a lo que supuso la acogida del graffiti por parte del arte Pop en las décadas de los ochenta y los noventa, en él muchos artistas vieron una forma de agitación política y ruptura con los academicismos artísticos. Cuestión que ya sería planteada a principios del siglo XX por movimientos como el arte agitprop ${ }^{4}$, que ya comienzan a beber de las fuentes del graffiti, del comic o del cine underground, para ampliar o aislar elementos icónicos de la cultura artística y realizar, con ellos, una descontextualización satírica. En ese sentido, la misma estrategia del Pop Art utiliza muchas descontextualizaciones de este tipo, extrayendo elementos de la sociedad de consumo para ponerlos en entredicho. Para Gillo Dorfles (1969: 206):

Hoy, el pop-art puede enseñarnos quizás a ver lo poco o mucho de bueno -o, en todo caso, de interesante- que anida en determinados productos mecánicos e industriales de los que nos servimos constantemente y que hasta ayer habíamos ignorado, desde un punto de vista estético y social.

\footnotetext{
${ }^{4}$ Agitprop (propaganda de agitación o agitación y propaganda) es una estrategia política, generalmente de tendencia comunista, difundida a través del arte o la literatura, usando como métodos la agitación y la propaganda para influenciar sobre la opinión pública y de este modo obtener réditos políticos. "En arte es utilizado para impulsar creencias ideológicas, específicamente para difundir los ideales del comunismo en Rusia en el periodo inmediatamente posterior a la Revolución de 1917" (Chilvers, 2001: 17).
} 
$\mathrm{Al}$ establecer, tanto la tendencia pop como el graffiti, fuentes situadas en la sociedad de masas, podemos observar que mantienen muchas similitudes, desde dos vertientes diferenciadas: mientras el artista pop extrae elementos de la sociedad de consumo para adular o criticar a los iconos que produce la sociedad de masas, así como a los medios que los difunden, el artista del mundo del graffiti emplea estos mismos elementos con la intención de destapar el lado oscuro de las cosas cotidianas, evidenciando el uso político de lo cotidiano. Según apunta Francesco Pellizzi (2008: 24):

No hay forma de arte más intrínsecamente contradictoria: tan intensamente privada, casi solipsista, y a la vez, en apariencia, tan pública, o libremente compartida. De modo similar, su elocuencia se apoya en un lenguaje comunitario $-\mathrm{y}$ por lo tanto sujeto a modas - y a la vez idiosincrático, puesto que sus tendencias suelen ser autogeneradas, crípticas y patentes, anónimas y claramente personales: una especie de firma, pero la firma de un alias, y siempre de un 'delincuente'.

En ese sentido, un artista significativo que unirá estas dos esferas, la elitista y la callejera, será Jean-Michel Basquiat (Nueva York, 1960), que representa el caso del artista callejero fagocitado por el sistema institucional, y que poco a poco ve coartada - de alguna manera y aunque su obra siga pareciendo 'fres-

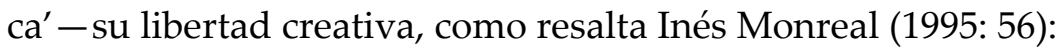

JMB se alejó paulatinamente del automatismo para intentar la integración de sus garabatos en una auténtica Obra de Arte. Todo ello no le haría perder, en ningún caso, el aspecto efímero y volátil de las creaciones elaboradas con rapidez, casi con premura.

Hecho que denota esta integración entre las dos tendencias fue, en 1984, una colaboración que realizaron Warhol, Basquiat y Francesco Clemente, a partir de la sugerencia del galerista Bruno Bischofberger, que posteriormente continuarían los dos primeros, materializándose en lienzos de gran escala. A Warhol le entusiasmaba la espontaneidad y energía del joven Basquiat, quien aconsejó al primero pintar a mano alzada. Fruto de esa colaboración es la obra Ailing Ali in Fight for Life (1984-85).

Desde el hecho explicado, el caso de Keith Haring es análogo al de Basquiat: venido de la escritura de graffitis en las calles, va abandonando sus orígenes para encontrarse con otras formas de expresión. En ambos casos, será el contacto con gente relacionada con el mundo del arte lo que hace que sus trayectorias cambien, pasando del 'garabato' callejero a una producción auténti- 
camente artística. De esta promiscuidad entre la pintura institucional y el arte de la calle, surge algo que no se quedará en un fenómeno sólo local, tal y como Delphine Renard explica:

De un fenómeno artístico local, el graffiti se convierte en un estilo en el contexto del arte internacional; algunos antiguos escritores de graffiti o ex-estudiantes de arte, al término del actual período de transición sabrán apropiárselo para extraer desarrollos originales (Renard, 1984: 20).

De lo que deducimos que el graffiti supondrá una forma nueva para aquellos que, una vez acabadas sus carreras de arte y seducidos por él, pretendan comenzar a experimentar. El graffiti, asimismo, se irá incorporado poco a poco en los planes de estudio de algunos centros de enseñanza artística. Este fue el recorrido seguido por Haring que, después de estudiar arte en la Ivy School of Art de Pittsburgh y en la Escuela de Artes Visuales de Nueva York, se lanza a dibujar graffitis inspirados en los dibujos animados de la televisión.

Aunque el fenómeno del graffiti nace en Estados Unidos, pronto comenzará a extenderse al resto del mundo. Por ejemplo, alguien que desde Europa comienza a recoger el testigo legado por estos pintores de reminiscencias callejeras será A. R. Penk, artista neoexpresionista, con cierta similitud a Haring, que, además, fija su atención el arte primitivo egipcio y en algunos trabajos de Paul Klee, como dirá Anna María Guasch (2000: 260):

Penck crea un lenguaje de signos simples y esquemáticos con el afán de que sean universalmente comprensibles. En sus pinturas 'sistemáticas' rehúye deliberadamente los cánones clásicos y las formas orgánicas para plantear una formalización casi geométrica de carácter arcaico y primitivo, una especie de jeroglíficos fácilmente descifrables, que llenan el cuadro a modo de all over.

El ejemplo de Penk demuestra que en Europa existe otra forma de entender ese arte callejero que viene de América, quizá porque exista una raíz más profunda, más allá de las modas neoyorquinas, en la memoria de las inscripciones de los muros, que, como explicábamos al principio, poseen una historia mucho más antigua de lo que parece.

Otro de los ejemplos que atestigua este hecho es Jean Dubuffet, quien acuña el término Art Brut ${ }^{5}$, para referirse a los no profesionales que trabajan fue-

\footnotetext{
${ }^{5}$ Art Brut es un término concebido por Jean Dubuffet para describir el arte creado fuera de los límites de la cultura oficial, concepto que sería posteriormente acogido por el crítico de arte 
ra de las normas estéticas impuestas por la institución artística. En su búsqueda de crear un arte libre despejado de preocupaciones intelectuales, crea figuras elementales y pueriles inspiradas en los dibujos de los niños, los criminales y los dementes; seres infrahumanos, deformes y grotescos. Dubuffet, considerado un precursor de muchas de las derivas plásticas que se darán posteriormente, se sentirá especialmente atraído por la exploración de las inscripciones de los muros de París, una fascinación que él mismo verbaliza así:

Es verdad que la atracción que ejerce sobre mí el muro es extremadamente fuerte, que mi vida psíquica está poderosamente unida al muro, y que todas mis pinturas, cualquiera que sea el tema que traten, están constantemente atravesadas por mi extremado gusto por el muro6.

Asimismo, al hablar de Dubuffet, no podemos olvidar a un artista que desde su propio nombre está ligado íntimamente al lenguaje de los muros, constituyendo un eje central en su obra, nos referimos a Antoni Tápies. Su obra se halla repleta de evocaciones a las inscripciones y dibujos de los muros callejeros, que no vienen de influencias graffiteras neoyorquinas, aunque posteriormente irá sumando a su técnica el uso de sprays, sino de su recuerdo de las paredes pintadas de la guerra y la postguerra española. Catástrofes cuyo recuerdo se va abandonando, mediante señales y dibujos, en los muros que presenciaban, como testigos mudos y depositarios, las vivencias de la gente. Así se va forjando la memoria de Tápies, a la que se van sumando acentos culturales cercanos a los movimientos artísticos a los que poco a poco va teniendo acceso. De esta forma el muro de la urbe se convierte para él, según relata, en todo un símbolo de:

(...) separación, enclaustramiento, lamentación, cárcel, testimonio del paso del tiempo; superficies lisas, serenas, blancas; superficies torturadas, viejas, decrépitas; señales de huellas humanas, de objetos, de los elementos naturales, sensación de lucha, de esfuerzo; de destrucción, de cataclismo; o de construcción, de surgimiento, de equilibrio; restos de amor, de dolor, de asco, de desorden; prestigio romántico de las ruinas; aportación de elementos orgánicos, formas sugerentes de ritmos naturales y del movimiento espontáneo de la materia;

Roger Cardinal en 1972. El interés de Dubuffet se dirige principalmente hacia las manifestaciones artísticas llevadas a cabo por pacientes de hospitales psiquiátricos.

${ }^{6}$ Dubuffet, J (1967): Carta a A. Pieyre de Mandiargues (18 de octubre de 1957), en Prospectus et tous écrits suivants. Gallimard. París, p. 470. Citado en Webel, S: “Jean Dubuffet o el lenguaje de los muros" (AA.VV.: 2008: 13). 
sentido paisajístico, sugestión de la unidad primordial de todas las cosas; materia generalizada; afirmación y estimación de la cosa terrena; posibilidad de distribución variada y combinada de grandes masas, sensación de caída, de hundimiento, de expansión, de concentración; rechazo del mundo, contemplación interior, aniquilación de las pasiones, silencio, muerte; desgarramiento y torturas, cuerpos descuartizados, restos humanos; equivalencias de sonidos, rasguños, raspaduras, explosiones, tiros, golpes, martilleos, gritos, resonancias, ecos en el espacio; meditación de un tema cósmico, reflexión para la contemplación de la tierra, del magma, de la lava, de la ceniza; campo de batalla; jardín; terreno de juego; destino de lo efímero (Tàpies, 2008: 11-12).

Como contrapunto a la evocadora memoria europea acerca del muro callejero, para no dejar un sabor tan 'sombrío', volvamos de nuevo a América, para finalizar esta relación entre el graffiti y la pintura, con la obra Wendy White (Deep River, 1971). Esta artista mezcla en sus pinturas la tipografía y el grafitti realizado con pintura en aerosol, adheriendo, a veces, objetos a la superficie. White busca intencionalmente cierto efecto de provisionalidad y aire distendido, muy cercano al carácter general que inunda la estética de nuestro tiempo; como si estuviera realizando una prueba con la superficie, el soporte, lo escultórico o la instalación específica, en una escritura automática que va de lo gestual al campo de color. Esta obra, de carácter eminentemente experimental, se alimenta, en definitiva, de la plástica fresca de la urbe. El graffiti y la mezcla de planos que establece con sus pinturas, en un encuentro automático a modo de palimpsesto indescifrable entre las palabras y sus sentidos, asemejan a esos tags - que en la actualidad podemos encontrar en un vagón de tren, por ejemplo- de los que hablábamos al comienzo de este apartado. Barry Schwabsky (2011: 320) habla así de su proceso:

Existe una asociación inevitable con la pintura en spray del graffiti, pero con una gran ampliación de posibilidades para los matices. Las señales se sienten tanto táctiles como mediadas, en proporciones de interminables variables. El uso de las letras, ya sean pintadas o construidas, ayudan a activar las partes del cerebro que leen en sincronía, pero también a veces en conflicto, con las partes que se ven, incluso si lo que hay que leer es, finalmente, inescrutable.

\section{4.- Conclusiones.}

Mediante el somero repaso ofrecido en el presente artículo, en el sentido de la relación de dos expresiones urbanas - como son el cartel y el graffiti- 
con la pintura, hemos comprobado cómo la ciudad siempre está presente en muchos artistas como fuente de inspiración constante. Asimismo, la puesta en común que ofrece el espacio urbano, sirve de nexo convergente entre lo que se ha denominado alta cultura, que en el contexto aquí expuesto sería la representada por la institución artística - donde situamos a la pintura, regulada mediante normas devenidas de su tradición -, y la llamada baja cultura, que aquí corresponde a la expresión de una masa social informe - debido a la multitud de intereses que alberga y necesita manifestar-, no regulada, en principio, pero que se puede llegar a estudiar a través del análisis de los nuevos medios que, en este caso, suponen el cartel o el graffiti.

El choque de estos dos polos (la alta cultura de la tradición pictórica y la baja cultura del cartel y el graffiti) - su puesta en conjunción e imbricación-, además de poner a la ciudad como el escenario primordial propicio para el diálogo cultural, nos demuestra el grado de absorbencia o permeabilidad que mantiene la pintura, como disciplina tradicional, con todas esas nuevas expresiones que va generando la ciudad, así como al contrario.

En ese sentido, la perspectiva del transcurso aquí relatado - que bien pudiera extrapolarse a otras disciplinas - nos demuestra el vector interdisciplinar al que nos dirigimos actualmente. Algo que, como consecuencia, acarrea el borrado de límites entre las disciplinas y medios. Una situación que ahora, en el siglo XXI, hemos de asimilar y aceptar en grado positivo pues, como hemos podido observar, muchas de las transformaciones acaecidas en los medios tratados no se hubieran producido de no haber sido concebidos de manera abierta a la experimentación e interferencia mutua, sin prejuicios ante la velocidad del progreso en el que la ciudad, el individuo y el artista se vieron insertos a partir de la Revolución Industrial.

\section{Bibliografía.}

AA.VV. (2001): El cartel moderno francés. El espectáculo está en la calle. Aldeasa. Madrid.

AA.VV. (2008): Jean Dubuffet o el idioma de los muros, catálogo de exposición. Círculo de Bellas Artes. Madrid.

AA.VV. (2013): Albert Oehlen. Moderne Farbkozepte, catálogo de exposición. La Casa Encendida. Madrid. 
BARNICOAT, John (1972): Los carteles. Su historia y su lenguaje. Gustavo Gili. Barcelona.

CHILVERS, Ian (2001): Diccionario del arte del siglo XX. Editorial Complutense. Madrid.

DORFLES, Gillo (1969): Nuevos ritos, nuevos mitos. Lumen. Barcelona.

GUASCH, Anna María (2000): El arte último del siglo XX. Del posminimalismo a lo multicultural. Alianza Forma. Madrid.

GUBERN, Román (1987): La mirada opulenta. Gustavo Gili. Barcelona.

GUBERN, Román (1997): Medios icónicos de masas. Historia 16. Madrid.

LOZANO BARTOLOZZI, Maria del Mar (2000): Wolf Vostell (1932-1998). Nerea. Hondarribia.

MAFFESOLI, Michel (1987): “La hipótesis de la centralidad urbana”. Revista de Occidente. Madrid, $\mathrm{n}^{\circ} 73$.

MonReAL, Inés (1995): “Jean Michel Basquiat”. El Híbrido. Zaragoza, nº 2.

PelliZZI, Francesco (2008): "Jean-Michel Basquiat: contra el muro", en catálogo de exposición Jean-Michel Basquiat. Ahuyentando fantasmas. Fundación Marcelino Botín. Santander.

RENARD, Delphine (1984): “Graffiti writers, graffiti artists". Art Press, mayo. New York.

SCHWABSKY, Barry (2011): Vitamin P2. New perspectives in Painting. Phaidon. New York.

TÁPIES, Antoni (2008): “Comunicación sobre el muro”, en catálogo de exposición Graffiti Brassaï, Círculo de Bellas Artes. Madrid.

TOMÁs, Facundo (1998): Escrito, pintado. Dialéctica entre escritura e imágenes en la conformación del pensamiento europeo. Visor. Madrid. 